\title{
Mortality from all cancers of asbestos factory workers in east London 1933-80
}

\author{
G Berry, M L Newhouse, J C Wagner
}

Department of Public Health and

Community Medicine, University of Sydney,

New South Wales 2006, Australia

G Berry

Formerly TUC Centenary Institute of Occupational Health, London School of Hygiene and Tropical Medicine, London, UK M L Newhouse (died 15 February 2000)

Formerly MRC

Pneumoconiosis Unit, Penarth, UK

J C Wagner (died 25 May 2000)

Correspondence to:

Dr G Berry

geoffb@pub.health.usyd.edu.au

Accepted 6 July 2000

Abstract

Objective-To give the observed and expected deaths due to cancer at all separate sites in asbestos workers in east London, and to analyse these for overall effect and exposure-response trend.

Methods-The mortality experience of a cohort of over 5000 men and women followed up for over 30 years since first exposure to asbestos has been extracted.

Results-There was a large excess of deaths due to cancer (537 observed, 222 expected). Most of these were due to cancer of the lung (232 observed, 77 expected) and pleural (52) and peritoneal (48) mesothelioma. The exposure-response trend for all these three causes was highly significant. There was also an excess of cancer of the colon ( 27 observed, 15 expected) which was significantly related to exposure. There were significant excesses of cancer of the ovary, of the liver, and of the oesophagus but with no consistent relation to exposure.

Conclusions-The excess risk of cancer after exposure to asbestos was mainly due to cancer of the lung and mesothelioma. An exposure related excess of cancer of the colon was also detected but the possibility that some of these deaths may

Table 1 Observed and expected deaths for all men and women

\begin{tabular}{|c|c|c|c|}
\hline Site (ICD-7 code) & Observed & Expected & Obs/Exp $(95 \% C I)$ \\
\hline All neoplasms (140-239) & 537 & 221.58 & $2.42(2.22$ to 2.64$)$ \\
\hline Buccal cavity and pharynx $(140-148)$ & 5 & 3.24 & $1.54(0.50$ to 3.60$)$ \\
\hline Oesophagus (150) & 12 & 5.78 & $2.08(1.07$ to 3.63$)$ \\
\hline Stomach (151) & 28 & 23.09 & $1.21(0.81$ to 1.75$)$ \\
\hline Small intestines (152) & 2 & 0.46 & $4.33(0.52$ to 15.6$)$ \\
\hline Colon (153) & 27 & 14.78 & $1.83(1.20$ to 2.66$)$ \\
\hline Rectum (154) & 10 & 10.10 & $0.99(0.47$ to 1.82$)$ \\
\hline Liver, gall and bile ducts $(155-156)$ & 10 & 3.76 & $2.66(1.28$ to 4.89$)$ \\
\hline Pancreas (157) & 8 & 9.26 & $0.86(0.37$ to 1.70$)$ \\
\hline Larynx (161) & 3 & 1.84 & $1.63(0.34$ to 4.76$)$ \\
\hline Lung $(162-163,231)$ & 232 & 76.96 & $3.01(2.64$ to 3.43$)$ \\
\hline Breast $(170)$ & 12 & 10.48 & $1.15(0.59$ to 2.00$)$ \\
\hline Uterus-cervix (171) & 6 & 2.70 & $2.22(0.81$ to 4.83$)$ \\
\hline Uterus-other, and unspecified $(172,174)$ & 0 & 1.28 & $0.00(0.00$ to 2.87$)$ \\
\hline Ovary (175) & 9 & 3.56 & $2.53(1.16$ to 4.80$)$ \\
\hline Prostate (177) & 5 & 7.14 & $0.70(0.23$ to 1.63$)$ \\
\hline Testis (178) & 1 & 0.82 & $1.22(0.03$ to 6.79$)$ \\
\hline Kidney (180) & 2 & 3.64 & $0.55(0.07$ to 1.99$)$ \\
\hline Bladder (181) & 10 & 6.91 & $1.45(0.69$ to 2.66$)$ \\
\hline Melanoma (190) & 0 & 1.39 & $0.00(0.00$ to 2.65$)$ \\
\hline Skin-other (191) & 0 & 0.69 & $0.00(0.00$ to 5.35$)$ \\
\hline Brain and CNS $(193,223,237)$ & 8 & 7.66 & $1.04(0.45$ to 2.06$)$ \\
\hline Thyroid (194) & 0 & 0.55 & $0.00(0.00$ to 6.65$)$ \\
\hline Bone (196) & 0 & 0.89 & $0.00(0.00$ to 4.14$)$ \\
\hline Soft tissue (197) & 0 & 0.60 & $0.00(0.00$ to 6.10$)$ \\
\hline Hodgkin's disease (201) & 2 & 2.14 & $0.93(0.11$ to 3.37$)$ \\
\hline Myeloma (203) & 3 & 2.13 & $1.41(0.29$ to 4.12$)$ \\
\hline Leukaemia (204) & 7 & 5.29 & $1.32(0.53$ to 2.72$)$ \\
\hline Other lymphoma $(200,202)$ & 4 & 3.61 & $1.11(0.30$ to 2.84$)$ \\
\hline Mesothelioma-pleural & 52 & - & $61(46 \text { to } 80)^{\star}$ \\
\hline Mesothelioma-peritoneal & 46 & - & $54(40 \text { to } 72)^{\star}$ \\
\hline Other sites & 33 & 10.81 & \\
\hline
\end{tabular}

^Rate per 100000 person-years have been peritoneal mesotheliomas could not be excluded. There was no consistent evidence of exposure related excesses at any other site.

(Occup Environ Med 2000;57:782-785)

Keywords: asbestos; cancer; exposure-response

The mortality of a group employed at an asbestos factory in the east end of London has been described in several publications. ${ }^{1-9}$ The group consisted of about 3000 men and 700 women factory workers and of 1400 laggers (insulators). The factory workers were involved in the manufacture of asbestos textiles and products - such as prefabricated cement pipes. Crocidolite was used until the mid-1950s as well as amosite and chrysotile asbestos. The laggers worked on contracts outside the factory with intermittent and varying exposure, and some had worked as insulators before their employment by this factory. The men were those first employed between May 1933 and 1964 who worked at the factory for at least 30 days, and the women were those first employed between 1936 and 1942. The most recent analyses were of the follow up to June and December 1980 for women and men respectively. Since that analysis follow up of the groups stopped. The previous publications reported exposure related excess deaths due to lung cancer and pleural and peritoneal mesothelioma. Several other cancer types were considered in some of the papers but the complete listing of all cancer sites has not been published. In view of the interest that occurs from time to time on the possibility that asbestos exposure increases risk of cancer at several sites it was considered appropriate to give the results for all sites while summary data are still available.

\section{Methods}

Causes of death were coded according to the 7 th revision of the international classification of diseases (ICD-7). The cause of death coded was that given on the death certificate except that where a confirmed mesothelioma was found, the mesothelioma was taken as the cause of death irrespective of what was on the death certificate. Cancer deaths have been taken as ICD-7 codes 140 to 239 inclusive. In previous reports codes 140 to 205 have been used. The inclusion of codes 210 to 229 (benign neoplasms) and 230-239 (neoplasm of unspecified nature) involved only one extra death (ICD-7 237, neoplasm of brain or other part of nervous system). 
The mortality was assessed by comparing the number of observed deaths with the number expected based on sex, age, and period specific death rates for England and Wales, calculated with the person-years method, and the tables of person-years produced for the most recent previous analysis. ${ }^{8}$ The first 10 years after first employment in the factory were excluded. In previous analyses the mortality covered the period from 1943 for men and from 1946 for women (10 years after first entry into the study) but because of the availability of cancer death rates for all the sites attention is now restricted to mortality from 1951 onwards. The effect of this change is trivial as the period excluded contained only 12 (expected 11.7) of the 1249 deaths from all causes and two (expected 2.0) of the 539 due to cancer.
Exposure was classified by degree (low to moderate versus severe) and duration (2 years or less and more than 2 years). Fuller details of the classification of jobs were given by Newhouse. ${ }^{1}$ Briefly, the low to moderate category included administrative workers, store workers, those involved in the manufacture of insulating material with less than $20 \%$ asbestos, and maintenance staff. Workers in this category did not work regularly in areas where the 1931 asbestos regulations applied. The severe intensity category included workers involved in sectional pipe making, the manufacture of insulating material with a high asbestos content, workers in the textile and mattress sections, openers, disintegrators, and those employed in the disposal of dust. These jobs were all covered by the 1931 Asbestos Regulations. The terms

Table 2 Observed and expected mortality for separate exposure groups

\begin{tabular}{|c|c|c|c|c|c|c|c|c|}
\hline & \multicolumn{8}{|c|}{ Observed / expected deaths } \\
\hline & \multicolumn{3}{|l|}{ Women } & \multicolumn{5}{|l|}{ Men } \\
\hline & Low/mod & $\begin{array}{l}\text { Severe } \\
<2 y\end{array}$ & $\begin{array}{l}\text { Severe } \\
>2 y\end{array}$ & $\begin{array}{l}\text { Low/mod } \\
<2 y\end{array}$ & $\begin{array}{l}\text { Low } / \text { mod } \\
>2 y\end{array}$ & $\begin{array}{l}\text { Severe } \\
<2 y\end{array}$ & $\begin{array}{l}\text { Severe } \\
>2 y\end{array}$ & Laggers \\
\hline \multirow{2}{*}{ All neoplasms } & 12 & 60 & 57 & 49 & 57 & 102 & 128 & 72 \\
\hline & 7.27 & 26.02 & 11.18 & 40.03 & 32.11 & 45.86 & 32.56 & 26.54 \\
\hline \multirow[t]{2}{*}{ Buccal cavity and pharynx } & 0 & 0 & 0 & 1 & 1 & 2 & 1 & 0 \\
\hline & 0.09 & 0.30 & 0.13 & 0.63 & 0.49 & 0.68 & 0.50 & 0.42 \\
\hline \multirow[t]{2}{*}{ Oesophagus } & 1 & 2 & 2 & 2 & 2 & 2 & 1 & 0 \\
\hline & 0.16 & 0.51 & 0.22 & 1.11 & 0.88 & 1.26 & 0.87 & 0.77 \\
\hline \multirow[t]{2}{*}{ Stomach } & 1 & 1 & 3 & 4 & 3 & 9 & 5 & 2 \\
\hline & 0.67 & 1.96 & 0.88 & 4.48 & 3.67 & 4.97 & 3.85 & 2.61 \\
\hline \multirow[t]{2}{*}{ Small intestines } & 1 & 0 & 0 & 0 & 0 & 0 & 0 & 1 \\
\hline & 0.02 & 0.05 & 0.02 & 0.08 & 0.06 & 0.10 & 0.07 & 0.06 \\
\hline \multirow{2}{*}{ Colon } & 0 & 2 & 1 & 3 & 3 & 3 & 8 & 7 \\
\hline & 0.72 & 2.29 & 1.00 & 2.48 & 2.01 & 2.70 & 1.97 & 1.62 \\
\hline \multirow[t]{2}{*}{ Rectum } & 0 & 4 & 0 & 2 & 0 & 3 & 0 & 1 \\
\hline & 0.34 & 1.08 & 0.47 & 1.89 & 1.55 & 2.05 & 1.53 & 1.18 \\
\hline \multirow{4}{*}{$\begin{array}{l}\text { Liver, gall bladder and bile } \\
\text { ducts } \\
\text { Pancreas }\end{array}$} & 0 & 2 & 0 & 1 & 3 & 2 & 2 & 0 \\
\hline & 0.15 & 0.47 & 0.21 & 0.66 & 0.52 & 0.76 & 0.54 & 0.45 \\
\hline & 1 & 1 & 1 & 2 & 0 & 2 & 1 & 0 \\
\hline & 0.29 & 0.95 & 0.41 & 1.71 & 1.37 & 1.98 & 1.38 & 1.17 \\
\hline \multirow[t]{2}{*}{ Larynx } & 0 & 0 & 0 & 0 & 0 & 2 & 1 & 0 \\
\hline & 0.02 & 0.08 & 0.04 & 0.39 & 0.31 & 0.43 & 0.33 & 0.24 \\
\hline \multirow{2}{*}{ Lung } & 2 & 14 & 21 & 24 & 23 & 43 & 67 & 38 \\
\hline & 0.77 & 2.97 & 1.22 & 16.06 & 12.94 & 19.09 & 13.56 & 10.35 \\
\hline \multirow[t]{2}{*}{ Breast } & 1 & 5 & 6 & 0 & 0 & 0 & 0 & 0 \\
\hline & 1.57 & 6.09 & 2.59 & 0.05 & 0.04 & 0.06 & 0.04 & 0.03 \\
\hline Uterus-cervix & 1 & 3 & 2 & & & & & \\
\hline & 0.39 & 1.61 & 0.70 & & & & & \\
\hline Uterus-other, and & 0 & 0 & 0 & & & & & \\
\hline unspecified & 0.22 & 0.74 & 0.32 & & & & & \\
\hline Ovary & 2 & 2 & 5 & & & & & \\
\hline & 0.54 & 2.12 & 0.90 & & & & & \\
\hline Prostate & & & & 1 & 1 & 0 & 1 & 2 \\
\hline & & & & 1.73 & 1.67 & 1.57 & 1.43 & 0.74 \\
\hline Testis & & & & 0 & 1 & 0 & 0 & 0 \\
\hline & & & & 0.18 & 0.11 & 0.20 & 0.09 & 0.23 \\
\hline Kidney & 0 & 0 & 0 & 0 & 1 & 0 & 1 & 0 \\
\hline & 0.08 & 0.28 & 0.12 & 0.70 & 0.53 & 0.84 & 0.54 & 0.54 \\
\hline Bladder & 0 & 1 & 0 & 2 & 1 & 1 & 3 & 2 \\
\hline & 0.13 & 0.39 & 0.17 & 1.43 & 1.24 & 1.54 & 1.20 & 0.80 \\
\hline Melanoma & 0 & 0 & 0 & 0 & 0 & 0 & 0 & 0 \\
\hline & 0.04 & 0.18 & 0.08 & 0.24 & 0.16 & 0.28 & 0.15 & 0.26 \\
\hline Skin-other & 0 & 0 & 0 & 0 & 0 & 0 & 0 & 0 \\
\hline & 0.02 & 0.07 & 0.03 & 0.13 & 0.11 & 0.14 & 0.10 & 0.08 \\
\hline Brain-CNS & 0 & 3 & 0 & 0 & 2 & 2 & 1 & 0 \\
\hline & 0.19 & 0.78 & 0.33 & 1.41 & 0.93 & 1.77 & 0.98 & 1.27 \\
\hline Thyroid & 0 & 0 & 0 & 0 & 0 & 0 & 0 & 0 \\
\hline & 0.04 & 0.12 & 0.05 & 0.08 & 0.06 & 0.09 & 0.06 & 0.06 \\
\hline Bone & 0 & 0 & 0 & 0 & 0 & 0 & 0 & 0 \\
\hline & 0.03 & 0.09 & 0.04 & 0.17 & 0.12 & 0.19 & 0.13 & 0.12 \\
\hline Soft tissue & 0 & 0 & 0 & 0 & 0 & 0 & 0 & 0 \\
\hline & 0.02 & 0.07 & 0.03 & 0.11 & 0.08 & 0.13 & 0.08 & 0.10 \\
\hline Other lymphoma & 0 & 1 & 1 & 0 & 1 & 0 & 0 & 1 \\
\hline & 0.10 & 0.35 & 0.15 & 0.67 & 0.48 & 0.80 & 0.48 & 0.58 \\
\hline Myeloma & 0 & 0 & 0 & 0 & 0 & 1 & 2 & 0 \\
\hline & 0.07 & 0.25 & 0.11 & 0.38 & 0.30 & 0.45 & 0.29 & 0.28 \\
\hline Hodgkin's disease & 0 & 0 & 0 & 0 & 0 & 0 & 1 & 1 \\
\hline & 0.04 & 0.16 & 0.07 & 0.42 & 0.27 & 0.51 & 0.28 & 0.39 \\
\hline Leukaemia & 0 & 1 & 1 & 2 & 2 & 0 & 0 & 1 \\
\hline & 0.16 & 0.57 & 0.25 & 0.98 & 0.73 & 1.12 & 0.71 & 0.77 \\
\hline
\end{tabular}


Table 3 Observed numbers of mesotheliomas, rates per 100000 person-years and adjusted rates for 25 years follow up for separate exposure groups

\begin{tabular}{|c|c|c|c|c|c|c|c|c|}
\hline & \multicolumn{3}{|l|}{ Women } & \multicolumn{5}{|l|}{ Men } \\
\hline & Low/mod & $\begin{array}{l}\text { Severe } \\
<2 y\end{array}$ & $\begin{array}{l}\text { Severe } \\
>2 y\end{array}$ & $\begin{array}{l}\text { Low } / \text { mod } \\
<2 y\end{array}$ & $\begin{array}{l}\text { Low/mod } \\
>2 y\end{array}$ & $\begin{array}{l}\text { Severe } \\
<2 y\end{array}$ & $\begin{array}{l}\text { Severe } \\
>2 y\end{array}$ & Laggers \\
\hline \multicolumn{9}{|l|}{ Mesotheliomas (n): } \\
\hline Pleural & 1 & 9 & 4 & 4 & 6 & 9 & 12 & 7 \\
\hline Peritoneal & 0 & 7 & 4 & 1 & 4 & 11 & 13 & 6 \\
\hline Total & 1 & 16 & 8 & 5 & 10 & 20 & 25 & 13 \\
\hline Person-years & 2277 & 10222 & 4647 & 15193 & 9333 & 17966 & 8858 & 16795 \\
\hline Rate & 44 & 156 & 172 & 33 & 107 & 111 & 282 & 77 \\
\hline Adjusted person-years & 2942 & 15048 & 6018 & 13043 & 7537 & 19221 & 8120 & 7075 \\
\hline Adjusted rate & 34 & 106 & 133 & 38 & 133 & 104 & 308 & 184 \\
\hline
\end{tabular}

low to moderate and severe are relative to the period during which the factory operated, and the exposures in the low to moderate jobs were usually higher than those specified in the 1969 Asbestos Regulations. ${ }^{7}$ Amosite, chrysotile, and crocidolite were all used and much of the exposure was to mixed types. It was not possible to isolate groups exposed to a single fibre type. $^{8}$ The laggers (all men) were kept as a separate group. Most of the workers in all groups had been followed up for over 20 years, $41 \%$ of the male and $80 \%$ of the female production workers had been followed up for more than 30 years, whereas $9 \%$ of the laggers had been followed up beyond 30 years. ${ }^{8}$

The ratio of observed to expected deaths was used as a measure of excess mortality, and significance was calculated by taking the observed number as a Poisson variable. The exact confidence interval of the ratio was derived with the relation between the Poisson and the $\chi^{2}$ distributions. For assessment of an exposureresponse relation the exposure groups were ranked in increasing order of exposure as low to moderate (all durations), severe (2 years or less), laggers, severe (greater than 2 years) based on the excess mortality due to lung cancer. The exposure-response relation was assessed by a trend $\chi^{2}$ test. ${ }^{10}$ For many of the sites the expected number of cases was small and the exposure-response assessed with an exact test computed with StatXact. ${ }^{11}$ Two tailed significance levels are given and for exact tests these are double the one tail probability.

For mesotheliomas, as the expected number was very low, the incidence was expressed as an absolute rate. Trend with exposure has been assessed by taking the expected numbers of mesotheliomas in the four exposure groups as proportional to person-years weighted by time since first exposure raised to a power of 3.5, and the rates have been adjusted to 25 years since first exposure.

Results

Table 1 shows the comparison of observed and expected mortality over the whole group of men and women. Those classified as other sites are peritoneum (ICD-7 158) not confirmed as mesothelioma (four); endocrine (ICD-7 195, two); thoracic secondary (ICD-7 165, one); and other unspecified (ICD-7 199, 26). As well as pleural and peritoneal mesotheliomas there were five sites with a significant excess of deaths: lung (relative risk (RR) 3.0, 95\% confidence interval (95\% CI) 2.6 to 3.4 ), liver (RR

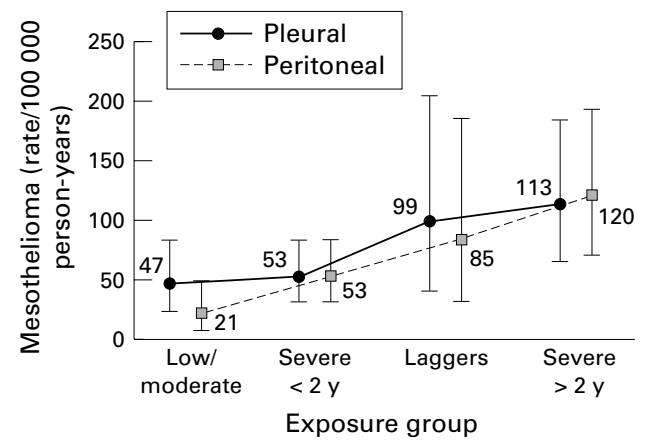

Figure 1 Exposure-response relations for pleural and peritoneal mesotheliomas. Mesothelioma rates are per 100000 person-years adjusted to 25 years after first exposure. The $95 \%$ confidence intervals are shown.

$2.7,95 \%$ CI 1.3 to 4.9 ), ovary (RR $2.5,95 \%$ CI 1.2 to 4.8 ), oesophagus (RR 2.1, 95\% CI 1.1 to 3.6) and colon (RR $1.8,95 \%$ CI 1.2 to 2.7 ). In table 2 the observed and expected mortality are shown for the different groups of subjects. In table 3 the observed numbers of mesotheliomas and the rates and adjusted rates are given. For the seven sites with a significant overall excess there were four that had a significant trend with exposure: lung $(\mathrm{p}<0.001)$, peritoneal mesothelioma $(\mathrm{p}<0.001)$, pleural mesothelioma $(p=0.011)$, and colon $(p=0.017)$. For cancer of the ovary the significance level for the exposure trend was 0.18 , but there was a significant excess in women with severe exposure of more than 2 years. For cancer of the liver the excess was distributed across all the exposure groups and the exposure trend was not significant $(p=0.77)$. This was also the case for cancer of the oesophagus $(p=0.98)$. The only other site for which the exposure-trend relation was significant at even the $10 \%$ level was the breast $(p=0.08)$; there was a nonsignificant excess in women with severe exposure of more than 2 years but little overall excess at this site.

The trend relations are shown in figures 1 and 2 for the four sites which are in excess overall and have a significant relation with exposure. The increasing risk of mesothelioma with increasing exposure is clear (fig 1), but stronger for the peritoneum than for the pleura. There was also a steady trend in relative risk of lung cancer with increasing exposure (fig 2). The excess in cancer of the colon occurred only in the laggers and in men with severe exposure for more than 2 years (table 2 ). 


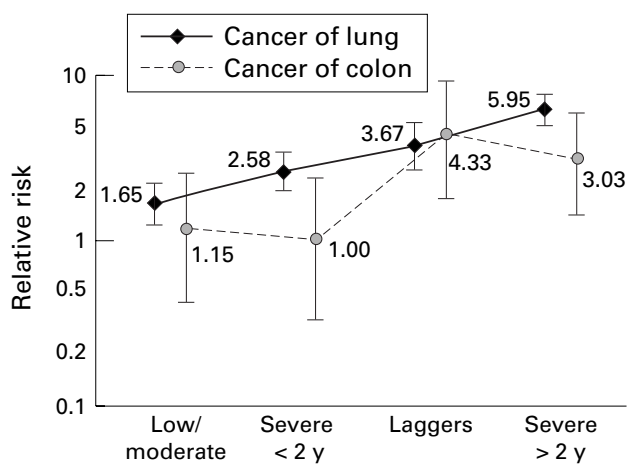

Exposure group

Figure 2 Exposure-response relations for cancer of the lung and cancer of the colon. Rates are relative risks compared with national rates adjusted for sex, age, and period. The $95 \%$ confidence intervals are shown.

\section{Discussion}

The overall excess was assessed on all men and women. There was evidence of excess lung cancer in the lowest exposure group (low to moderate 49 observed to 29.8 expected) and 16 mesotheliomas occurred in this group. Therefore, the exposure was sufficient in all exposure groups to produce an effect related to asbestos. The excess deaths due to cancer of the lung and both pleural and peritoneal mesothelioma and the exposure-response relations for these three causes are well established. The only other site which had a significant excess and a significant exposure-response relation was the colon (ICD-7 153; RR 1.8, 95\% CI 1.2 to $2.7, \mathrm{p}=0.017)$. In our previous report results for the wider grouping of gastrointestinal cancer (ICD-7 150-158) were given and an overall excess noted but without a significant relation with exposure. ${ }^{8}$ For this combined grouping there was a significant excess (observed 101, expected 67.2, RR 1.5, 95\% CI 1.2 to 1.8 ) but the exposure-response was nonsignificant $(\mathrm{p}=0.10)$. For colorectal cancer (ICD-7 152-154) there was a significant excess (observed 39, expected 25.3, RR 1.5, 95\% CI 1.1 to 2.1) but again a non-significant exposure-response $(p=0.10)$. The significant and exposure related excess of cancer of the colon was diluted in the wider groups by cancer of the stomach, rectum, and pancreas, which showed little excess and cancer of the oesophagus and liver, which showed excesses not strongly related to exposure. The excess of cancer of the colon was confined to men who had worked as laggers or been severely exposed for more than 2 years.

As with all mortality studies the results depend on the accuracy of cause of death information. To be able to compare the observed number of deaths with the expected calculated from national records the cause of death as recorded on the death certificate was accepted except that some deaths were reclassified as due to mesothelioma, and some originally classified as mesothelioma were not confirmed as such, on review of pathological material. ${ }^{2}$ Of the 52 pleural mesotheliomas 37 had been coded as ICD-7 163, 11 as lung cancer (ICD-7 162), and four as other sites. Of 46 peritoneal mesotheliomas 26 had been coded as ICD-7 158, nine as other unspecified (carcinomatosis) ICD-7 199, six as cancer of the gastrointestinal tract (two stomach ICD-7 151, three rectum ICD-7 154, one pancreas ICD-7 157), one as cancer of the ovary (ICD-7 175), and four as other causes. It was not possible to check all cancer deaths as pathological material was not always accessible and it is not known for how many of the 27 deaths from cancer of the colon the pathological material was checked. Although none of the peritoneal mesotheliomas identified had been certified as cancer of the colon, three had been certified as cancer of the rectum, an adjacent site, so it cannot be excluded that a few of the deaths certified as due to cancer of the colon may have been peritoneal mesotheliomas. Therefore, it cannot be accepted that there is an excess of cancer of the colon attributable to asbestos unless there is support from other studies of asbestos workers.

Many of the sites have low observed and expected mortality. Cancer at these sites cannot contribute much to the total effect of exposure in terms of the absolute number of excess deaths compared with the large excesses from cancer of the lung and mesothelioma. For rare causes an excess of relative risk would be difficult to establish from a single study and a meta-analysis is required. Such a meta-analysis has recently been carried out for cancer of the kidney. ${ }^{12}$ The results given in this paper provide the information necessary for any future metaanalysis study of asbestos workers. We are grateful to Professor Julian Peto (Institute of Cancer
Research) who provided the death rates for the cancer sites for England and Wales from 1951 in electronic form.

1 Newhouse ML. A study of the mortality of workers in an asbestos factory. Br F Ind Med 1969;26:294-301.

2 Newhouse ML, Wagner JC. Validation of death certificates in asbestos workers. Br f Ind Med 1969;26:302-7.

3 Newhouse ML, Berry G, Wagner JC, et al. A study of the Newhouse ML, Berry G, Wagner JC, et al. A study of the
mortality of female asbestos workers. Br $\mathcal{F}$ Ind Med 1972;29:134-41.

4 Berry G, Newhouse ML, Turok M. Combined effect of asbestos exposure and smoking on mortality from lung cancer in factory workers. Lancet 1972;ii:476-9.

5 Newhouse ML, Berry G. Asbestos and laryngeal carcinoma [letter]. Lancet 1973;ii:615.

6 Newhouse ML, Berry G. Predictions of mortality from mesothelial tumours in asbestos factory workers. $\mathrm{Br}$ F Ind Med 1976;33:147-51.

7 Newhouse ML, Berry G. Patterns of mortality in asbestos factory workers in London. Ann NY Acad Sci 1979;330: factory

8 Newhouse ML, Berry G, Wagner JC. Mortality of factory workers in east London 1933-80. Br f Ind Med 1985;42:411 .

9 Berry G, Newhouse ML, Antonis P. Combined effect of asbestos and smoking on mortality from lung cancer and mesothelioma in factory workers. Br F Ind Med 1985;42: $12-18$.

10 Armitage P, Berry G. Statistical methods in medical research, 3rd ed. Oxford: Blackwell, 1994:410.

11 Cytel Software Corporation. StatXact: statistical software for exact non-parametric inference, user manual version 2 . Cambridge, MA: CYTEL Software Corporation, 1991.

12 Sali D, Boffetta P. Kidney cancer and occupational exposure to asbestos: a meta-analysis of occupational cohort studies. Cancer Causes Control 2000;11:37-47. 